\title{
REVISTA BRASILERA DE
}

AGRICULTURA IRRIGADA

Revista Brasileira de Agricultura Irrigada v.9, nº.5, p. 326 - 334, 2015

ISSN 1982-7679 (On-line)

Fortaleza, CE, INOVAGRI - http://www.inovagri.org.br

DOI: $10.7127 /$ rbai.v9n500326

Protocolo 326.15 - 27/05/2015 Aprovado em 09/09/2015

\section{PRODUTIVIDADE DO MANJERICÃO (Ocimum basilicum L.) FERTIRRIGADO UTILIZANDO VINHAÇA CONCENTRADA}

\author{
L. F. Palaretti ${ }^{1}$, A. B. Dalri ${ }^{1}$, G. F. Dantas ${ }^{2}$, R. T. Faria ${ }^{1}$, W. F. Santos ${ }^{3}$; M. G. dos Santos ${ }^{4}$
}

\section{RESUMO}

No presente trabalho propõe-se avaliar a resposta do manjericão fertirrigado com vinhaça concentrada (VC) em diferentes doses. Utilizou-se delineamento em blocos inteiramente casualizados com seis tratamentos, sendo: $\mathrm{T} 0=0 \mathrm{~kg} \mathrm{ha}^{-1}$ de $\mathrm{K}_{2} \mathrm{O}$ (Controle); $\mathrm{T} 1=50 \mathrm{~kg} \mathrm{ha}^{-1} \mathrm{de}$ $\mathrm{K}_{2} \mathrm{O} ; \mathrm{T} 2=100 \mathrm{~kg} \mathrm{ha}^{-1}$ de $\mathrm{K}_{2} \mathrm{O}$; T3 = $150 \mathrm{~kg} \mathrm{ha}^{-1}$ de $\mathrm{K}_{2} \mathrm{O} ; \mathrm{T} 4=200 \mathrm{~kg} \mathrm{ha}^{-1}$ de $\mathrm{K}_{2} \mathrm{O}$; T5 = $250 \mathrm{~kg}$ $\mathrm{ha}^{-1}$ de $\mathrm{K}_{2} \mathrm{O}$ e seis repetições. Em todos os tratamentos foi aplicada uréia para reposição de $100 \%$ da recomendação de nitrogênio para a cultura. O cultivo foi realizado em vasos em ambiente protegido no período de 09/2013 a 12/2013. Foram avaliadas a altura de planta, diâmetro do caule, massa fresca e seca da raiz, volume da raiz, área foliar, massa fresca e seca de folhas e inflorescência, massa fresca e seca do caule, produtividade da massa fresca e seca das folhas. Não ocorreu efeito significativo na altura de planta, massa fresca e seca das raízes e volume radicular. Para o diâmetro do caule e área foliar ajustou-se modelos de regressão quadrática com doses ótimas de 165 e $240,77 \mathrm{~m}^{3} \mathrm{ha}^{-1}$, respectivamente. A interação entre as demais características com as doses de VC foram explicadas por regressão linear.

Palavras-chave: biomassa, fertilização, casa de vegetação.

\section{PRODUCTIVITY BASIL (Ocimum basilicum L.) FERTIRRIGATION USING CONCENTRATED VINASSE}

\begin{abstract}
This study aims to elucidate the behavior of fertilized basil with concentrated vinasse (VC) at different doses. We adopted the design in a completely randomized design with six treatments and six repetitions: Witness $\mathrm{T} 0=0 \mathrm{~kg} \mathrm{ha}^{-1}$ de $\mathrm{K}_{2} \mathrm{O}$ (Controle); $\mathrm{T} 1=50 \mathrm{~kg} \mathrm{ha}^{-1}$ de $\mathrm{K}_{2} \mathrm{O}$; $\mathrm{T} 2=100 \mathrm{~kg}$ ha $^{-1}$ de $\mathrm{K}_{2} \mathrm{O}$; T3 = $150 \mathrm{~kg} \mathrm{ha}^{-1}$ de $\mathrm{K}_{2} \mathrm{O}$; T4 $=200 \mathrm{~kg} \mathrm{ha}^{-1}$ de $\mathrm{K}_{2} \mathrm{O}$; T5 = $250 \mathrm{~kg} \mathrm{ha}^{-1}$ de $\mathrm{K}_{2} \mathrm{O}$. All treatments were applied urea for replacement of $100 \%$ of recommended nitrogen for the crop. Cultures were grown in pots in a protected environment in the period 09/13 to 12/13. The response of the culture of the basil doses of VC was evaluated by plant height, stem diameter, fresh and dry weight of root, root volume, leaf area, fresh and dry weight of leaves and inflorescence, fresh and

\footnotetext{
${ }^{1}$ Prof. Doutor, Depto de Engenharia Rural UNESP/FCAV, Jaboticabal - SP. Email: lfpalaretti@fcav.unesp.br

${ }^{2}$ Mestre, Doutorando UNESP/FCAV, Jaboticabal - SP: Email: geffson@hotmail.com

${ }^{3}$ Acadêmico do curso de Eng. Agronômica UNESP/FCAV, Jaboticabal - SP. Email: fabel.willian@gmail.com

${ }^{4}$ Mestre, Doutorando UNESP/FCAV, Jaboticabal - SP: Email: miqueiassjp@yahoo.com.br
} 
dry weight of stem , yield of fresh and dry leaves. There was no significant effect on plant height, fresh and dry weight of roots and root volume. To stem diameter and leaf area set quadratic regression models with optimal doses of 165 and $240.77 \mathrm{~m}^{3} \mathrm{ha}^{-1}$, respectively. The interaction between the other characteristics with doses of VC were explained by linear regression.

Keywords: biomass, fertilization, greenhouse

\section{INTRODUÇÃO}

O manjericão (Ocimum basilicum Linn.), pertencente à família Lamiaceae, é conhecido popularmente por alfavaca, alfavaca-cheirosa e basílico. De porte ereto e ramificado com aproximadamente $1 \mathrm{~m}$ de altura, têm folhas onduladas de coloração variando de verde a avermelhado e flores dispostas em racemos eretos. Seu ciclo pode ser anual ou perene em função da forma de condução e localidade de cultivo.

No Brasil, o manjericão é cultivado em pequenas propriedades rurais que normalmente comercializam as folhas verdes ("in natura") para uso como condimento alimentar aromático.

Em propriedades rurais no Nordeste do País, o manjericão tem despertado interesse econômico como matéria prima para a extração de óleo essencial (FAVORITO et al., 2011). Nestes locais, as folhas e ápices com inflorescências são utilizadas para obtenção do linalol via hidrodestilação em equipamentos específicos (LACHOWICZ et al., 1997).

O linalol tem uso direcionado para a indústria farmacêutica (MARTINS et al., 2010); alimentícia (BOZIN et al., 2006) e de cosméticos (TELCI et al., 2006). Na agricultura serve como base de partida para sínteses de acetato de linalila (FERNANDES et al., 2004).

A produtividade média anual de massa verde é de $15 \mathrm{t} \mathrm{ha}^{-1}$ (EMBRAPA, 2001) e varia em função da cultivar (BAHL et al., 2001) e do número de cortes realizados em ciclos perenes (MAY et al., 2008).

As informações relativas ao desempenho agronômico de plantas medicinais que relacionam a ecofisiologia com a produção do vegetal são escassas.
Todavia, a maior parte dos estudos têm se limitado à identificação dos compostos químicos e à farmacologia (HUSSAIN et al., 2008).

Excessos ou déficits de nutrientes e água podem causar efeitos diretos tanto no metabolismo primário, quanto no secundário (GOBBO-NETO et al., 2007), alterando o teor de fitofármacos do manjericão (BLANK et al., 2006), a composição química do óleo essencial e a produção de biomassa (SANTOS et al., 2004).

Produtividades de $4,3 \mathrm{t} \mathrm{ha}^{-1}$ de massa verde, com rendimento de 58,26 $\mathrm{kg} \mathrm{ha}^{-1}$ de óleo essencial foram obtidas com reposição de $100 \%$ da água evaporada pelo tanque classe A, na região de Presidente Prudente SP (PRAVUSCHI et al., 2010).

A deficiência de recomendações sobre a nutrição de plantas medicinais na literatura têm direcionado os produtores a adotarem manejos nutricionais de hortaliças. As incertezas incidem na quantidade, qualidade e fonte dos nutrientes. Estudos demonstram que adubações com fonte orgânica e mineral não influenciaram o rendimento do óleo essencial nem a produtividade de capimsanto (CARVALHO et al., 2005).

Na literatura é recomendada aplicações de até $300 \mathrm{~kg} \mathrm{ha}^{-1}$ de $\mathrm{N}-\mathrm{P}_{2} \mathrm{O}_{5}-\mathrm{K}_{2} \mathrm{O}$ (1:1:1) e de 50 a $75 \mathrm{~kg} \mathrm{ha}^{-1}$ de $\mathrm{N}$ por corte, em cobertura (SIMON, 1995). Muito embora existam resultados de aumento de biomassa e óleo essencial com doses de $200 \mathrm{~kg} \mathrm{ha}^{-1}$ de $\mathrm{N}$ (SINGH, 2002).

Em trabalhos realizados por Araújo et al. (2011), no estado da Bahia, sob ambiente protegido com doses crescentes de $\mathrm{N}$ e $\mathrm{K}$, não foi observado incremento no crescimento e na produção do manjericão, por outro lado, ocorreu redução em algumas 
características biométricas em condições de superdoses de $\mathrm{K}$.

Tendo em vista a carência de informações técnicas sobre a fertirrigação na cultura do manjericão, o objetivo do presente estudo foi avaliar o efeito de doses de vinhaça concentrada no crescimento do manjericão cultivado em estufa agrícola.

\section{MATERIAL E MÉTODOS}

O experimento foi conduzido na Universidade Estadual Paulista - Faculdade de Ciências Agrárias e Veterinárias, Câmpus de Jaboticabal, no setor de plasticultura, pertencente ao Departamento de Engenharia Rural, localizado a $21^{\circ} 15^{\prime} 22^{\prime \prime} S$ e $48^{\circ} 18^{\prime} 58^{\prime \prime} \mathrm{W}$ a 595 metros.

O clima da região, é subtropical úmido, Aw, segundo a classificação de Köppen, com inverno seco e ameno e verão quente e chuvoso, caracterizado por temperatura média anual de $22,20{ }^{\circ} \mathrm{C}$, média das temperaturas máximas de $24,30{ }^{\circ} \mathrm{C}$ e média das temperaturas mínimas de $18,60{ }^{\circ} \mathrm{C}$. As médias anuais de precipitação e evapotranspiração de referência somam $1.425 \mathrm{~mm}$ e $1.081 \mathrm{~mm}$, respectivamente.

As plantas de manjericão foram obtidas por semeadura em bandejas de isopor, preenchidas com substrato composto por fibra de coco e vermiculita em proporções iguais e acrescentado $6 \mathrm{~g} \mathrm{~L}^{-1}$ de fertilizante 624-12 e micronutrientes.

Em vasos agrícolas de polietileno preto de $8 \mathrm{~L}$, foram transplantadas 2 mudas, permanecendo a mais vigorosa. O substrato dos vasos foi composto por uma mistura de terra de barranco (90\%) e lodo de esgoto (10\%) aos 60 dias antes do transplante. A análise química resultou nos valores de: $\mathrm{P}_{\text {res. }}$ $=38 \mathrm{mg} \mathrm{dm}^{-3}$; matéria orgânica $=13,2 \mathrm{~g} \mathrm{dm}^{-}$ 3; $\mathrm{pH}=6,6 ; \mathrm{K}=2,15 \mathrm{mmol}_{\mathrm{c}} \mathrm{dm}^{3} ; \mathrm{Ca}=7,9$ $\operatorname{mmol}_{\mathrm{C}} \mathrm{dm}^{3} ; \mathrm{Mg}=6,8 \mathrm{mmol}_{\mathrm{c}} \mathrm{dm}^{3} \mathrm{e} \mathrm{V}=62 \%$.

$\mathrm{O}$ substrato foi corrigido de forma a elevar-se a soma de bases a $80 \%$ (RAIJ et al., 1996).

No fundo de cada vaso de polietileno recipiente foi instalada uma mangueira transparente de 3/8" de diâmetro para drenagem dos vasos quando necessário.

Os vasos foram acondicionados em ambiente protegido e dispostos sobre bancadas de alvenaria. $\mathrm{O}$ espaçamento utilizado foi de $0,20 \mathrm{~cm} \times 0,30 \mathrm{~cm}$, simulando um stand de 166 mil plantas ha ${ }^{-1}$.

As plantas foram irrigadas por um sistema composto por tubo de polietileno com diâmetro interno de 16 mm e emissores "on line" autocompensantes com vazão de 4 $\mathrm{L} \mathrm{h}^{-1}$. Em cada gotejador foi instalada uma cruzeta com quatro saídas e estas interligadas a quatro estacas através de microtubos, permitindo assim uma irrigação isolada de cada vaso com vazão de $1 \mathrm{~L}^{-1}$. A pressurização do sistema foi feita por uma motobombas de $1 / 2 \mathrm{Cv}$ e a filtragem por filtro de disco com 120 mesh.

As irrigações foram realizadas três dias por semana e o volume de água calculado em função da capacidade de vaso. Para a determinação da capacidade de vaso, o substrato do vaso foi saturado por capilaridade. Posteriormente os vasos foram submetidos a drenagem até peso constante e determinada a umidade do solo pelo método gravimétrico.

A vinhaça utilizada na experimentação foi adquirida em parceria a uma unidade de processamento de cana de açúcar da região. Após biodigestão e desidratação na unidade o resíduo líquido apresentou as seguintes características químicas: nitrogênio $(\mathrm{N})=$ $1,23 \mathrm{~kg} \mathrm{~m}^{-3}$ de vinhaça; fósforo $\left(\mathrm{P}_{2} \mathrm{O}_{5}\right)=0,43$ $\mathrm{kg} \mathrm{m} \mathrm{m}^{-3}$; potássio $\left(\mathrm{K}_{2} \mathrm{O}\right)=21,30 \mathrm{~kg} \mathrm{~m}^{-3} \mathrm{e}$ magnésio $(\mathrm{MgO})=1,39 \mathrm{~kg} \mathrm{~m}^{-3} ; \mathrm{pH}=4,40$; sódio $(\mathrm{Na})=0,15$; cobre $(\mathrm{Cu})=30,30 \mathrm{ppm}$; ferro $(\mathrm{Fe})=95,30 \mathrm{ppm}$; manganês $(\mathrm{Mn})=$ $16,60 \mathrm{ppm}$ e zinco $(\mathrm{Zn})=2,70 \mathrm{ppm}$.

O manejo fitossanitário da cultura foi realizado por meio do controle de pragas e doenças via pulverização de calda bordalesa e o de plantas invasoras via arranquio manual.

O experimento foi realizado seguindo um delineamento experimental inteiramente casualizado (DIC), com seis repetições, e seis tratamentos. Os seis tratamentos versaram sobre doses de potássio aportada pela 
vinhaça concentrada (VC) aplicada via fertirrigação, sendo: $\mathrm{T} 0=0 \mathrm{~kg} \mathrm{ha}^{-1}$ de $\mathrm{K}_{2} \mathrm{O}$ (Controle); $\mathrm{T} 1=50 \mathrm{~kg} \mathrm{ha}^{-1}$ de $\mathrm{K}_{2} \mathrm{O}$; $\mathrm{T} 2=100$ $\mathrm{kg} \mathrm{ha}^{-1}$ de $\mathrm{K}_{2} \mathrm{O}$; T3 = $150 \mathrm{~kg} \mathrm{ha}^{-1}$ de $\mathrm{K}_{2} \mathrm{O}$; T4 $=200 \mathrm{~kg} \mathrm{ha}^{-1}$ de $\mathrm{K}_{2} \mathrm{O}$; T5 = $250 \mathrm{~kg} \mathrm{ha}^{-1}$ de $\mathrm{K}_{2} \mathrm{O}$.

A recomendação de $100 \mathrm{~kg} \mathrm{ha}^{-1}$ de nitrogênio foi aplicada por meio da adição de uréia, parcelada, no transplante, aos 30 e aos 60 dias após o transplante.

A fertirrigação com vinhaça concentrada para todos os tratamentos foi parcelada em 10 aplicações a cada sete dias, iniciando um dia após o transplantio.

Cada parcela experimental foi composta por uma planta. Durante o estudo foram analisados: Altura de planta (AP) medida da base até a inflorescência apical, cm; Diâmetro do caule (DC) - medido com o auxílio de um paquímetro digital a $3 \mathrm{~cm}$ de altura do solo, cm; Massa fresca (MFR) e seca da raiz (MSR): via pesagem, gramas; Volume da raiz (VR), $\mathrm{cm}^{3}$; Massa fresca (MFF) e seca das folhas (MSF), gramas; Massa fresca (MFC) e seca do caule (MSC), gramas; Produtividade da massa fresca (PMF) e seca (PMS) das folhas, $\mathrm{t} \mathrm{ha}^{-1}$ e Área foliar (AF), $\mathrm{cm}^{2}$ - obtida com um medidor de área foliar Li-Cor 3100C. Para estimativa da área foliar foram coletadas aleatoriamente vinte folhas por repetição.

A verificação do efeito das doses da vinhaça concentrada (VC) nas variáveis estudadas foi feita por análise de variância e, posteriormente, elaboradas regressões lineares e polinomiais quadráticas, conforme a variável com o auxílio do programa computacional ASSISTAT.

Foi adotado o modelo de regressão que apresentasse maior coeficiente de determinação, e checada a normalidade dos resíduos pelo teste de Kolmogorov-Srmirnov.

\section{RESULTADOS E DISCUSSÃO}

Os volumes totais de vinhaça concentrada para o aporte da recomendação das doses de $\mathrm{K}_{2} \mathrm{O}$ no presente estudo foram: $\mathrm{T} 0=0 \mathrm{ml}$ VC (Controle); $\mathrm{T} 1$ = 14,14 ml VC;
$\mathrm{T} 2=28,28 \mathrm{ml} \mathrm{VC} ; \mathrm{T} 3=42,42 \mathrm{ml} \mathrm{VC} ; \mathrm{T} 4=$ 56,56 ml VC; T5 = 70,71 ml VC.

Para as condições de realização do estudo, não foi comprovado efeito significativo do potássio aportado via vinhaça concentrada nas características de altura de planta, massa fresca, massa seca e volume da raiz do manjericão.

A aplicação do teste de KolmogorovSrmirnov apontou normalidade dos resíduos de todas as regressões apresentadas neste estudo.

Interpretando a análise de regressão, foi observado efeito significativo das doses de vinhaça concentrada nos valores médios de diâmetro do caule, área foliar, massa fresca (MFF) e seca (MSF) das folhas, massa fresca (MFC) e seca do caule (MSC), produtividade da massa fresca e seca.

Para o diâmetro de caule foi ajustada a regressão polinomial quadrática $(\mathrm{p}<0,01)$, indicando uma relação funcional entre a dose de vinhaça aplicada e as características estudadas, com coeficiente de determinação de 0,82 (Figura $1 \mathrm{~A}$ ).

Foram observados acréscimos de valores no diâmetro do caule até a dose de $165 \%$ VC, equivalente a $165 \mathrm{~kg} \mathrm{ha}^{-1}$ de $\mathrm{K}_{2} \mathrm{O}$, com valor máximo de $1,18 \mathrm{~cm}$. A partir deste ponto, acréscimos na dose de vinhaça resultaram em decréscimo no diâmetro do caule. Este comportamento pode estar relacionado a uma possível resposta da planta à saturação de potássio aplicado, uma vez que no solo o teor de $\mathrm{K}^{+}$era médio, considerando-se culturas hortícolas. Entretanto, condições de fitotoxidez por excesso de $\mathrm{K}^{+}$são raramente observadas em sistemas de produção comercial (FILGUEIRA, 2008).

Estudos com doses crescentes de potássio na cultura do manjericão resultaram na redução do diâmetro do caule, quando aplicadas doses superiores a $150 \%$ de VC em um ciclo de 70 dias de cultivo (ARAÚJO et al., 2011).

A Figura 1B apresenta a relação entre a área foliar e o volume de vinhaça aplicado 
$(\mathrm{p}<0,01)$ e comportamento quadrático com

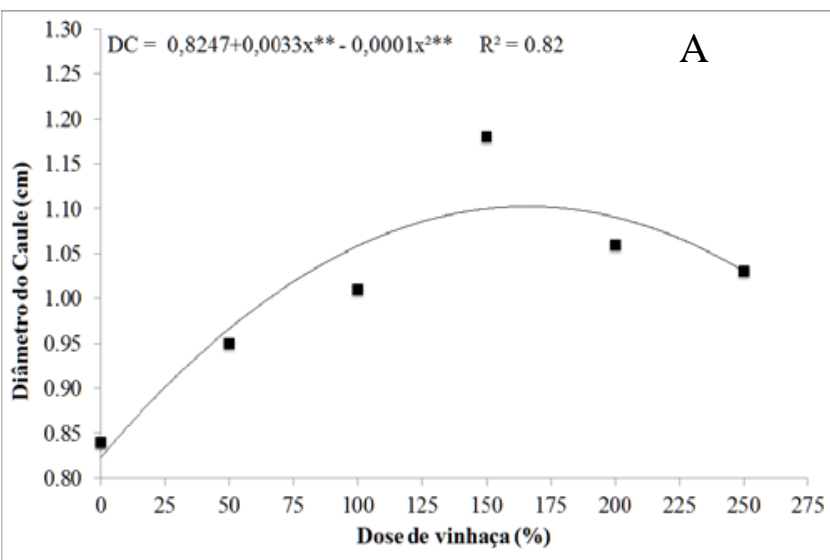

coeficiente de determinação de 0,95.

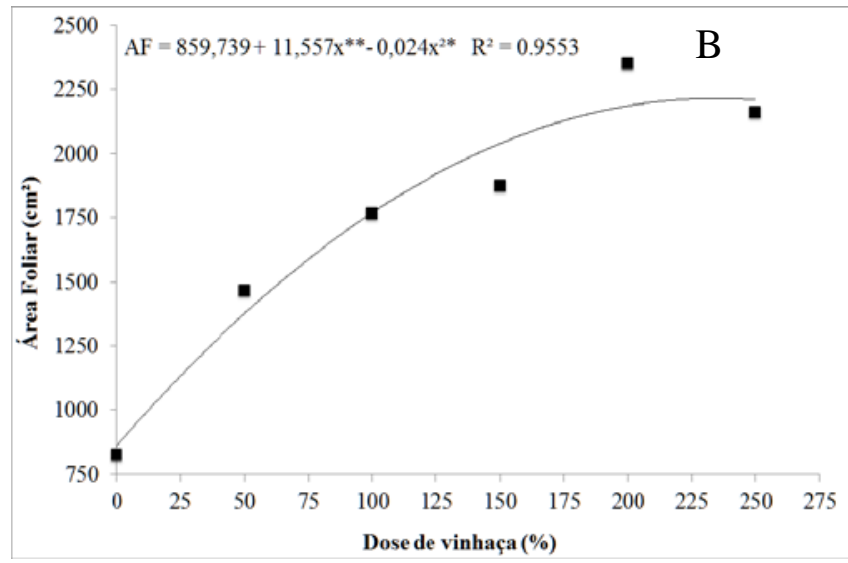

Figura 1 - Médias de diâmetro do caule (A) e área foliar (B) de manjericão cultivado em ambiente protegido e submetido a doses de vinhaça concentrada, Jaboticabal, 2013.

O crescimento máximo da área foliar foi alcançado na dose de $240,77 \%$ VC e decréscimo a partir deste, com valor de $2.350,90 \mathrm{~cm}^{2}$. O incremento foi $38,13 \%$ superior em relação ao controle, sem aplicação de vinhaça concentrada. Estes resultados são discordantes dos relatados por Araújo et al. (2011) que observaram decréscimo da área foliar com aplicações crescentes de potássio. Esta divergência pode ser atribuída ao fato de que neste estudo conjuntamente com a vinhaça concentrada foi feita a reposição total da exigência de nitrogênio, pela cultura, favorecendo a expansão foliar.

Segundo Filgueira (2008) o fornecimento de doses adequadas de $\mathrm{N}$ favorece o crescimento vegetativo, expansão da área foliar e a produção de fotoassimilados pela planta.

A relação funcional entre a massa fresca (MFF) e seca (MSF) de folhas com as doses de vinhaça concentrada é expressa por uma equação de $1^{\circ}$ grau com significância a $1 \%$ de probabilidade (Figura 2A-B). Não houve significância para os modelos de $2^{\circ}$ e $3^{\circ}$ grau.

Nas condições de realização deste estudo o valor máximo de massa fresca de folhas foi de 125,01 $\mathrm{g}$ planta $^{-1}$ e seca de 18,22 g planta $^{-1}$ no tratamento 5 (250\% VC).
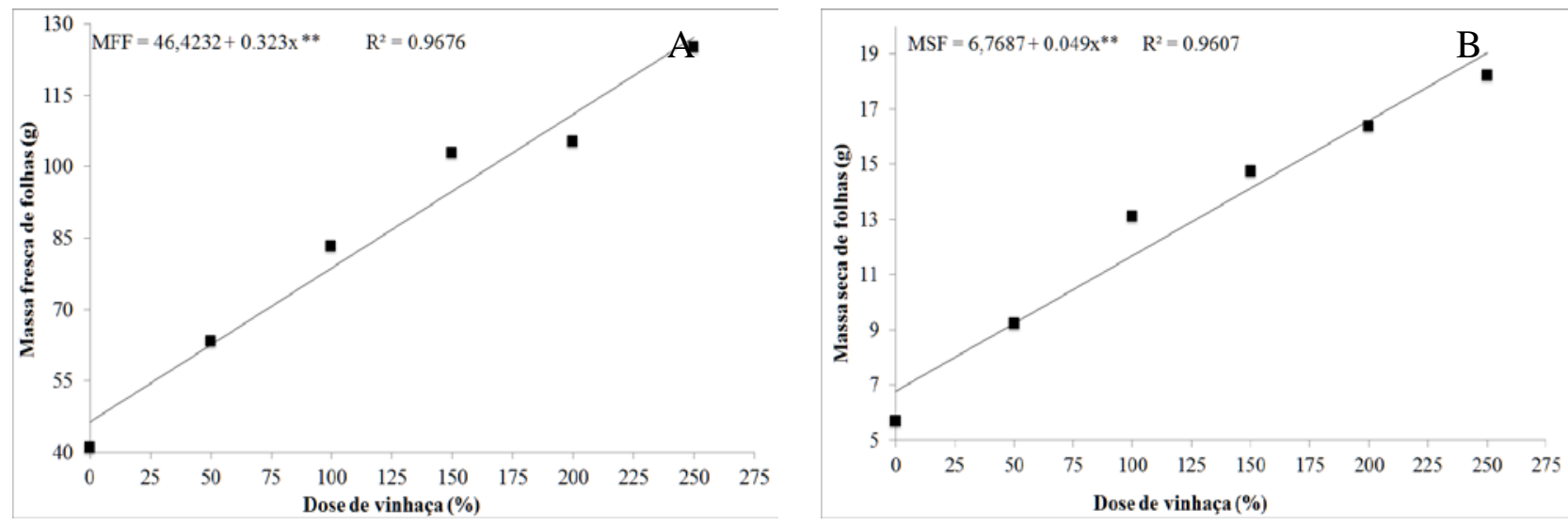

Figura 2 - Médias de massa fresca da folha (A) e massa seca da folha (B) de manjericão cultivado em ambiente protegido e submetido a doses de vinhaça concentrada. Jaboticabal, 2013.

Desta forma observa-se que acréscimos na dose de vinhaça concentrada acarretam o aumento da massa de folhas na cultura do manjericão. O coeficiente angular positivo 
demonstra que a massa fresca de folhas aumenta com os níveis ascendentes de vinhaça concentrada, indicando que para cada $1 \%$ de $\mathrm{K}_{2} \mathrm{O}$ aportado pela VC, no intervalo considerado, a massa fresca de folhas cresce 0,3229 g planta $^{-1}$.

Os valores crescentes de massa de folhas podem ser atribuídos à ausência de estresse hídrico, por estarem irrigadas, e a disponibilidade de nutrientes, principalmente nitrogênio e potássio, fornecidos pela vinhaça complementada pela uréia. Filgueira (2008) destaca a importância da interação entre o nitrogênio e o potássio, em que o primeiro atua diretamente na produção de massa verde de plantas e o outro na translocação de carboidratos e a melhoria na eficiência no uso de água.

Em estudos realizados por Araújo et al. (2011), o efeito da interação entre K e N (dose de 0 a $150 \mathrm{~kg} \mathrm{ha}^{-1}$ ) não foi significativa no incremento de massa de folhas; de forma contraria aos resultados apresentados por Blank et al., (2005).

Nas folhas dos vegetais os elementos preferencialmente encontrados são o $\mathrm{N}$, P e Ca (LARCHER, 2000). Desta forma, como o substrato utilizado para a experimentação apresentava níveis médios de $\mathrm{N}, \mathrm{P}$ e Ca para o cultivo de hortaliças, com a adição da VC, estas quantidades elevaram-se a níveis altos que podem ter influenciado positivamente na produção de massa de folhas. Singh (2002) verificou que a aplicação de $200 \mathrm{~kg} \mathrm{ha}^{-1}$ de $\mathrm{N}$ condicionou o aumento da biomassa e do teor de óleo essencial no manjericão.

A análise da massa fresca (MFC) e seca (MSC) do caule indica forte relação funcional de primeiro grau com a dose de vinhaça aplicada, pelos valores elevados do coeficiente de determinação (Figura 3A-B). Para a MFC e MSC os extremos superiores foram de 121,86 g e 18,54 $\mathrm{g}$ planta $^{-1}$ para o tratamento de $250 \%$ VC, respectivamente.
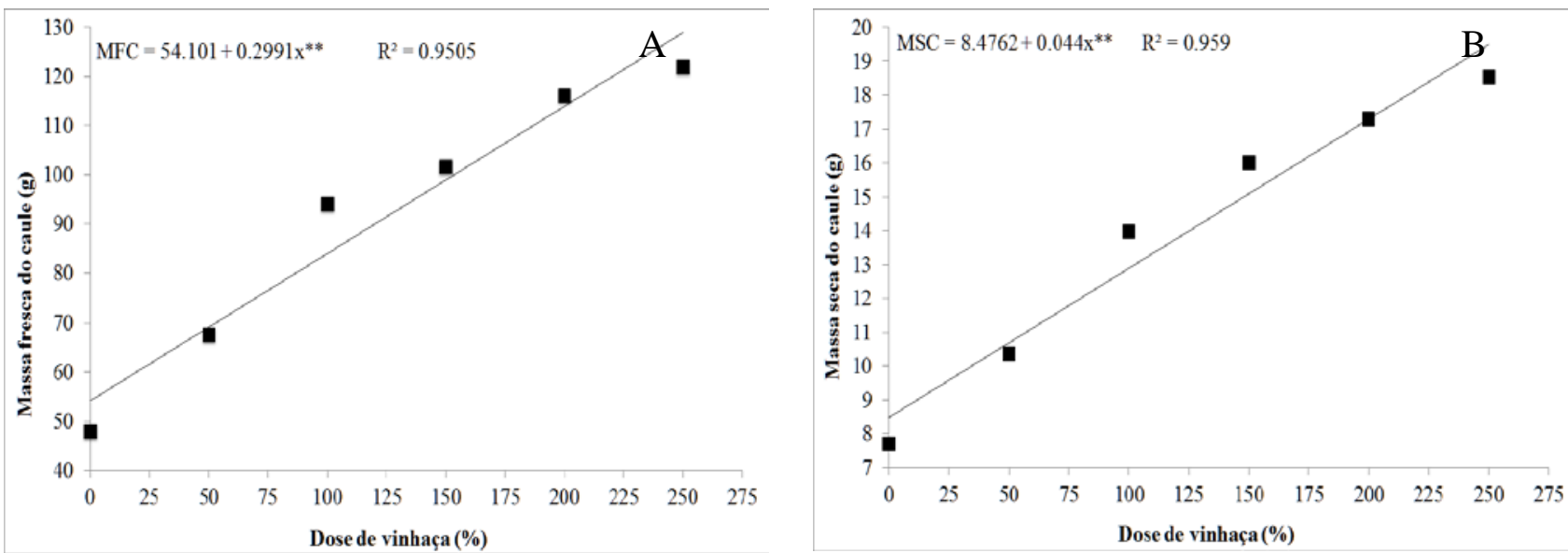

Figura 3 - Médias de massa fresca (MFC) e seca (MSC) (A-B) do caule de manjericão cultivado em ambiente protegido e submetido a doses de vinhaça concentrada. Jaboticabal, 2013.

Comportamento semelhante foi observado na massa fresca da folha; por outro lado, salienta-se que a linearidade observada no presente estudo pode não se manter em doses superiores a $250 \%$ VC.

Provavelmente em experimentos com doses supra ótimas de vinhaça concentrada serão observados decréscimos na massa de folhas, demonstradas pelo modelo de segundo grau.
A figura
4A-B
apresenta

produtividade total de massa fresca (PMF) e seca (PMS) de folhas considerando stand de 166 mil plantas $\mathrm{ha}^{-1}$. Observa-se um crescimento linear das características com o aumento das doses de vinhaça concentrada, com coeficientes de determinação próximos a unidade.

Os valores de 20,83 $\mathrm{t} \mathrm{ha}^{-1}$ de produtividade de massa fresca e 3,04 $\mathrm{t} \mathrm{ha}^{-1}$ de massa seca foram alcançados na dose de $250 \%$ VC. 

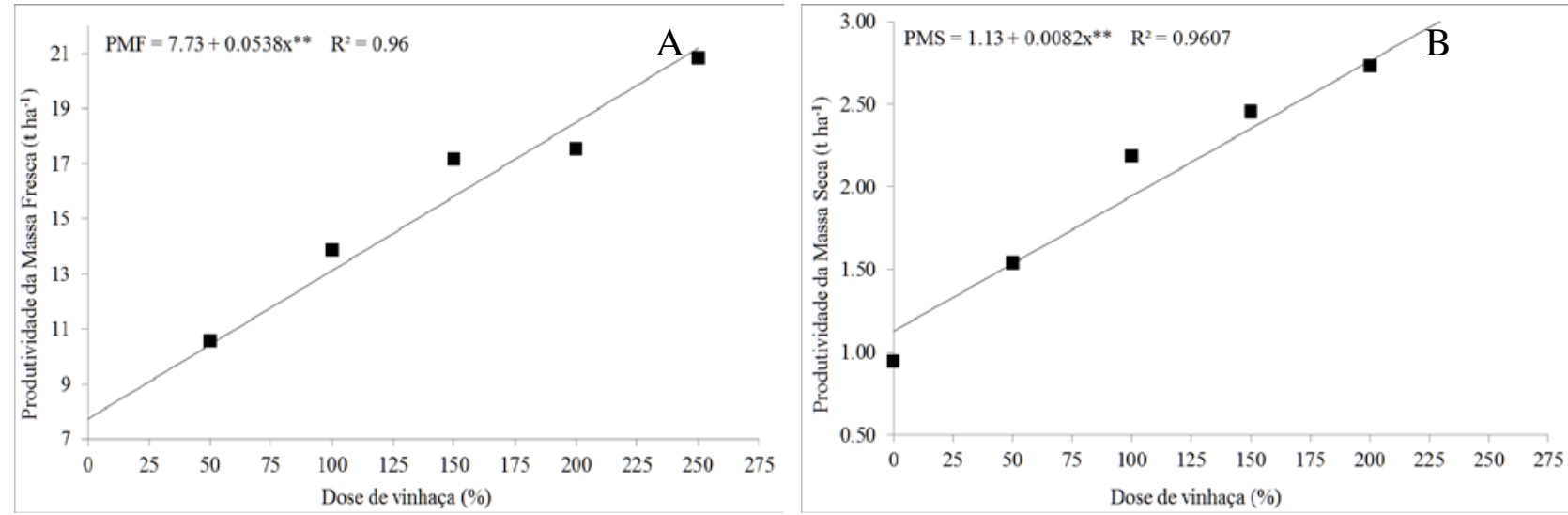

Figura 4 - Produtividade de massa fresca (PMF) e seca (PMS) de folhas de manjericão cultivado em ambiente protegido e submetido a doses de vinhaça concentrada. Jaboticabal, 2013.

O somatório da MFF e MFC, para composição da massa fresca da parte aérea, no tratamento de $250 \% \mathrm{VC}$, resulta em 246,87 g planta $^{-1}$, valor $36 \%$ superior aos 88,85 $\mathrm{g}$ planta $^{-1}$ observados no tratamento controle $(0 \% \mathrm{VC})$. Os valores de massa seca da parte aérea, obtidos com o mesmo raciocínio utilizado para massa fresca alcançam pontos percentuais da mesma magnitude.

O aumento linear observado na produção pode estar relacionado com a dotação hídrica total da planta (PRAVUSCHI et al., 2010), a reposição adequada de nutrientes, principalmente de $\mathrm{N}$, uma vez que o $\mathrm{K}$ não tem propiciado aumentos significativos de produtividade em culturas

\section{REFERÊNCIAS BIBLIOGRÁFICAS}

ARAÚJO, G. S.; MATSUMOTO, S. N.; SANTOS, M. A. F.; CÉSAR, F. R. C. F.; BONFIM, J. A. Crescimento de manjericão conduzido em cultivo protegido condicionado às doses de nitrogênio e doses supra ótimas potássio. Revista Ambiência, v.7, p. 265-277, 2011.

BAHL, J. R.; GARG, S. N.; BANSAL, R. P.. Yield and quality of school essential oil from the vegetative flowering and fruiting stage crops of Ocimum basilicum c. Kusumohak. Journal of Medicinal and Aromatic Plant Sciences, v. 22, p.743-746, 2001. herbáceas (FILGUEIRA, 2008; ARAÚJO et al., 2011) e o condicionamento do solo proporcionado pela elevada quantidade de material orgânico adicionado pela vinhaça concentrada.

\section{CONCLUSÃO}

O potássio aportado via aplicação de vinhaça concentrada propiciou o aumento das características biométricas. Para as características de produção, as doses aplicadas não foram suficientes para provocar o decréscimo nos valores, apresentando comportamento linear $\mathrm{e}$ crescente até a dose de 250\% VC.

BLANK, A. F.; SILVA P. A.; ARRIGONIBLANK, M. F.; SILVA-MANN, R.; BARRETO, M. C. V. Influência da adubação orgânica e mineral no cultivo de manjericão cv. Genovese. Ciência Agronômica, v.36, p. 175-180, 2005.

BLANK, A. F.; OLIVEIRA, A. S.; ARRIGONI-BLANK, M. F.; FAQUIN, V. Efeitos da adubação química e da calagem na nutrição de melissa e hortelã-pimenta. Horticultura Brasileira, v. 24, p. 195-198, 2006.

BOZIN, B.; MIMICA-DUKIC, N.; SIMIN, N.; ANACKOV, G. Characterization of the volatile composition of essential oils of some 
Lamiaceae species and the antimicrobial and antioxidant activities of the entire oils. Journal of Agricultural Food Chemistry, v. 54, p. 1822-1828, 2006.

CARVALHO, C. M.; COSTA, C. O. M.; SOUSA, J. S.; SILVA, R. H. D.; OLIVEIRA, C. L.; PAIXÃO, F. J. R. Rendimento da produção de óleo essencial de capim-santo submetido a diferentes tipos de adubação. Revista de biologia e ciências da terra, v.5, 2005.

EMBRAPA-HORTALIÇAS. Manjericão: Ocimum basilicum L. Porto Velho. (Série: "Plantas Medicinais" do Subprojeto de hortomatriz de plantas medicinais em Porto Velho - Rondônia), 2001.

FAVORITO, P. A.; ECHER, M. M.; OFFEMANN, L. C.; SCHLINDWEIN, M. D.; COLOMBARE, L. F.; SCHINEIDER, R. P.; HACHMANN, T. L. Características produtivas do manjericão (Ocimum basilicum L.) em função do espaçamento entre plantas e entre linhas. Revista Brasileira de Plantas Medicinais, v.13 n.spe, p. 582-586, 2011.

FERNANDES, P. C.; FACANALI, R.; TEIXEIRA, J. P. F.; FURLANI, P. R.; MARQUES, M. O. M. Cultivo de manjericão em hidroponia e em diferentes substratos sob ambiente protegido. Horticultura Brasileira, v. 22, p. 260-264, 2004.

FILGUEIRA, F. A. R. Novo manual de olericultura - 3. ed. Viçosa: UFV. 2008. 421p.

GOBBO-NETO, L.; LOPES, N. P. Plantas medicinais: fatores de influência no conteúdo de metabólitos secundários. Química Nova, v. 30, p. 374-381, 2007.

HUSSAIN, A. I.; ANWAR, F.; SHERAZI, S. T. H.; PRZYBYLSKI, R. Chemical composition, antioxidant and antimicrobial activities of basil (Ocimum basilicum) essential oils depends on seasonal variations. Food Chemistry, v. 108, p. 986-995, 2008.
LACHOWICZ, K. J.; JONES, G. P.; BRIGGS, D. R.; BIENVENU, F. E.; PALMER, M. V.; MISHRA, V.; HUNTER, M. M. Characteristics of plants and plant extracts from five varieties of basil (Ocimum basilicum L.) grown in Australia. Journal of Agricultural and Food Chemistry, v.45, n.7, p.2260-2265, 1997.

LARCHER, W. Ecofisiologia Vegetal. São

Carlos: Rima Artes e Textos, 2000. 531p.

MARTINS, A. G. L. A.; NASCIMENTO, A. R.; FILHO, J. E. M.; FILHO, N. E. M.; SOUZA, A. G.; ARAGÃO, N. E.; SILVA, D. S. V. Atividade antibacteriana do óleo essencial do manjericão frente a sorogrupos de Escherichia coli enteropatogênica isolados de alfaces. Revista Ciência Rural, v. 40, p. 1791-1796, 2010.

MAY, A.; BOVI, O. A.; MAIA, N. B.; BARATA, L. E. S.; SOUZA, R. C. Z.; SOUZA, E. M. R.; MORAES, A. R. A.; PINHEIRO, M. Q. Basil plants growth and essential oil yield in a production system with successive cuts. Bragantia, v. 67, p. 385-389, 2008.

PRAVUSCHI, P. R.; MARQUES, P. A. A.; RIGOLIN, B. H. M.; SANTOS, A. C. P. Efeito de diferentes lâminas de irrigação na produção de óleo essencial do manjericão (Ocimum basilicum L.). Acta Scientiarum Agronomy, v. 32, p. 687-693. 2010.

RAIJ, B. V.; CANTARELLA, H.; QUAGGIO, J. A.; FURLANI, A. M. O. Recomendações de adubação e calagem para o Estado de São Paulo. Campinas: Instituto Agronômico, 1996. 285 p.

SANTOS, T. T.; SANTOS, M. F.; MENDONÇA, M. C.; JÚNIOR, C. D. S.; SILVA-MANN, R.; ARRIGONI-BLANK, M. F.; BLANK, A. F. Efeito do estresse hídrico na produção de massa foliar e teor de óleo essencial em sambacaitá (Hyptis $\begin{array}{lll}\text { pectinata } & \text { L.). In: CONGRESSO }\end{array}$ BRASILEIRO DE OLERICULTURA, 44. 
Mato Grosso do Sul. Anais... Campo Grande: SOB, 2004. p. 1-4.

SIMON, J. E. Basil. West Lafayette: Purdue University, 1995. 6 p.

SINGH, M. Effect of nitrogen and irrigation regimes on the yiels and quality of sweet basil (Ocimum basilicum L.). Journal of
Spices and Aromatic Crops, v.11, p. 151154, 2002.

TELCI, I.; BAYRAMB, E.; YILMAZA, G.; AVCIB B. Variability in essential oil composition of Turkish basils (Ocimum basilicum L.). Biochemical Systematics and Ecology. v.34, n.6, p.489-497, 2006. 